\title{
Understanding Project Performance with Stochastic Interruption
}

\author{
Kazuaki Okubo $^{1, *(D)}$ and Makoto Okumura ${ }^{2}$ (iD \\ 1 Graduate School of International Cultural Studies, Tohoku University, Kawauchi 41, Aoba-ku, \\ Sendai 980-8576, Japan \\ 2 International Research Institute of Disaster Science, Tohoku University, Aramaki-Aoba 468-1, Aoba-ku, \\ Sendai 980-8572, Japan; makoto.okumura.b6@tohoku.ac.jp \\ * Correspondence: kazuaki.okubo.d5@tohoku.ac.jp
}

Citation: Okubo, K.; Okumura, M. Understanding Project Performance with Stochastic Interruption.

Sustainability 2022, 14, 2964. https:// doi.org/10.3390/su14052964

Academic Editors: Tatsuhito Kono and Nao Sugiki

Received: 28 January 2022

Accepted: 1 March 2022

Published: 3 March 2022

Publisher's Note: MDPI stays neutral with regard to jurisdictional claims in published maps and institutional affiliations.

Copyright: (c) 2022 by the authors. Licensee MDPI, Basel, Switzerland. This article is an open access article distributed under the terms and conditions of the Creative Commons Attribution (CC BY) license (https:// creativecommons.org/licenses/by/ $4.0 /)$.

\begin{abstract}
It is becoming increasingly important to implement projects with care on environmental conditions. Some projects can be carried out only during the allowable season and interrupted during other seasons. Such a project interruption is expected to affect the quality of the project's outcome through the decision-making of the stakeholders. This paper investigates the impact of interruption on the decision-making of the project owner and the contractor. We consider a project with some work after the interruption period (two-year project), the owner can select another option (one-year project) where all work is completed before the interruption period. If the fixed cost is higher relative to the benefit, our results show that the contractor prefers the one-year project, even when the owner selects the two-year project. We also represent the two threshold values of the interruption length that determine the owner's selection and relative quality of outcomes, respectively. It was found that a range of interruption length where the selected project does not provide the higher quality outcome.
\end{abstract}

Keywords: project management; stochastic interruption; dynamic optimization

\section{Introduction}

It is becoming important to implement infrastructure construction projects thoughtfully with care on environmental conditions in order to promote sustainable development. Sustainable Development Report 2021 [1] reported that the quality of infrastructure related to transportation, such as roads, ports, and railroads, is low in many regions and suggests that there are many challenges in infrastructure construction projects. There are many studies that imply challenges for high-performing projects by investigating critical factors that lower the project performance and case studies are being conducted worldwide from developed to developing countries, such as the United States (Shane et al. [2], Wambeke et al. [3]), Denmark(Larsen et al. [4]), Vietnam(Long et al. [5]), India (Doloi et al. [6]), Jordan (Al-Hazim et al. [7]), Nigeria (Elinwa and Joshua [8]) and multiple countries (Flyvbjerg et al. [9]). These studies mainly conducted interviews or questionnaire surveys to identify the factors that affect cost overrun, time delay, or low quality as the indicators of project performance. Long et al. [5], Doloi et al. [6] and Elinwa and Joshua [8] suggested the importance of appropriate planning to avoid cost overrun or time delay. Al-Hazim et al. [7] reported that land and weather conditions have the greatest impact on cost overrun and time delay in Jordan. Larsen et al. [4] stated the insufficiency of empirical data on quality due to the difficulty of defining the quality precisely in the construction project. Larsen et al. [4] is one of the studies that investigated critical factors which lower the quality. They found that unsettled or lack of project planning has great impacts on the project quality, and they also show that errors or omissions in construction work which is caused by the changes in conditions or circumstances would be a critical factor in determining the quality of the projects.

In some of the regions that need a lot of infrastructure construction, it can be difficult to keep working all the time because the weather varies so much throughout the year. A 
distinct rainy season can be found in the savannah climate regions, and it significantly affects the progress of projects such as infrastructure construction, especially long-term projects lasting over a year. There are some examples of thoughtful climate-adaptive projects, such as suspending the project during unsuitable periods and implementing it during more suitable periods. For example, in order to avoid an increase in the number of accidents caused by the loss of sustain function of the ground during the rainy season, road repair work is concentrated during the dry season when it is relatively easy to carry out the project [10]. If the project were to proceed in unsuitable periods, more work effort would be required, such as reinforcing the sustain function of the ground, and the environmental impact would be greater. A thoughtful climate-adaptive project has the potential to be a project to carry out with a smaller environmental impact. In order to promote such a project, it is required to develop appropriate project planning by taking into account the interruption periods associated with climatic conditions. Since climatic conditions vary from year to year, project management under uncertainty is relevant to this study. Recently, Hazir and Ulsoy [11] reviewed studies about project management under uncertainty and classified the various sources of uncertainty. They found that few studies had addressed environmental uncertainty caused by weather and seasonal factors. For example, Acebes et al. [12], as one of such few trials, examined the impact of frost risks, caused by low temperatures in the winter season, on the project duration, under the assumption that the project would be delayed by $25 \%$ when the temperature drops below $0{ }^{\circ} \mathrm{C}$. Although Acebes et al. [12] applied a critical path model which considers such a seasonal risk, Acebes et al. [12] did not assume the situations where the project is completely interrupted. We consider a project with some work after the interruption period (two-year project), the owner can select another option(one-year project) where all work is completed before the interruption period.

The critical-path model was also applied in other studies, such as Icmeli-Tukel and Rom [13], Kim et al. [14] and Bordley et al. [15]. Icmeli-Tukel and Rom [13] represented the advantage of the project schedule that maximizes the project quality compared to the schedule which minimizes [maximizes] project length [net present value] by applying a critical path model. Kim et al. [14] evaluated the quality loss by shortening the project length. Bordley et al. [15] examined the impact of ignoring deadline uncertainty on project performance, using a probabilistic critical-path model. These studies indicated critical path models are useful for analyzing the decision-making of an individual with considering the detail of processes. On the other hand, the quality of project outcome is also considered to be affected by the decisions of the stakeholders involved in the projects. Gutierrez and Kouvelis [16] pointed out that it is difficult for the critical-path model to account for the behavior of the stakeholders. Some studies analyzed the decision-making in projects by applying other models. Bellman [17] developed a dynamic programming model and analyzed project interruption, but did not consider the situation where projects are completely interrupted. Schwartz and Zozaya-Gorostiza [18] considered the decision-making in IT development projects and applied real options theory to examine the impact of cost uncertainty and abandoning decisions. Although these studies analyzed the decision-making under a multi-period setting, they only focused on the decision-making of one individual.

Mok et al. [19] reviewed the studies about mega construction projects, that involve multiple stakeholders. Mok et al. [19] pointed out that examining the impact of national culture on projects is one of the future research directions. This study considered the impact of region-specific climates, such as the rainy season in savanna climates. It is considered that this feature is consistent with the research direction shown in Mok et al. [19]. Ceric [20] reviewed papers related to principal-agent theory in construction project management and pointed out that few studies focused on the behavior of project owners. Zhu et al. [21] considered the decision-making of the project owner, contractor, and insurance company and assumed stochastic disturbances only affect the outputs of the contractor. Zhu et al. [21] did not explicitly specify the causes of disturbances, especially project interruption. Because Zhu et al. [21] considered a static framework, not a multi-period setting. Therefore, an 
analytical framework is needed for examining the impact of complete interruptions on the decision-making of multiple stakeholders in a multi-period setting. Our study is another trial to add an example of studies considering the stochastic disturbances that have a significant impact to interrupt a project completely, and it affects all of the stakeholders, such as the owner, and the contractor.

This study aims to examine the effect of the interruption on the decision-making of the owner who selects the project types, and the contractor who decides the quality of the project. First, we examine the impact of changes in the interruption length on the social benefit which comes from the decision-making of the owner and the contractor. Second, we consider that the owner can select one of the one-year and the two-year projects to maximize the social benefit. And then, we examine the differences in the owner's and the contractor's preferences for the two types of projects and represent the thresholds at which the preferences change. Furthermore, we also examine the effect of the variance of the interruption length on the project selection of the owner. Currently, global climate change is making the prediction of such an interruption more difficult. The timing of the rainy and dry seasons is changing due to the changes in global water cycle patterns. In some countries such as Botswana in Africa, the dry season is becoming longer and the rainfall in the rainy season is increasing [22,23]. Our framework will become increasingly important to promote sustainable development with the increase in uncertainty of climate conditions due to global warming.

This paper proceeds as follows. In Section 2, we represent our model framework. The behavior of the owner and the contractor is formulated. In Section 3, we study the properties of the project, e.g., the expected benefits, under various settings on the interruption. We conclude in Section 4.

\section{Model}

We consider a model in which an owner wishes to maximize the social benefit gained from a construction project. The social benefit becomes higher as the quality of the project's outcome becomes higher, and the owner wishes the project to be completed by a contractor. This project can be completed with multiple periods of effort by the contractor. The contractor determines the amount of effort each time to maximize the profit. The owner pays a reward to the contractor according to the completed amount at the completion time and determines the amount of reward to maximize the owner's expected benefit, by considering the response of the contractor. Thus, the contractor makes their decision as the reward is given.

If the project duration exceeds one year, then it is assumed that interruption periods will occur because of environmental conditions, such as the rainy season. Any year and subsequent year are divided by the interruption period, and the length of the interruption is stochastically determined. Both the owner and contractor only know the probability distribution of the length of the interruption. We develop a discrete-continuous multiperiod model to describe the behavior of the contractor and owner under such a condition.

\subsection{Behavior of the Contractor under Discrete-Continuous Multi-Period Setting}

\subsubsection{Profit Function of the Contractor}

In this model, the planning period is described by both continuous and discrete-time periods. We consider multiple years, described by an integer $n$, each consisting of multiple weeks, represented by the continuous number $t$. The integer $n \in \mathcal{N} \equiv\{1,2, \cdots, N\}$ describes multiple years, and the continuous number $t$ is used as an index to describe finer periods, such as weeks or day. $t$ is defined in each year as $t \in\left[t_{n}, \cdots, T_{n}\right], \forall n \in \mathcal{N}$, where $t_{n}$ denote the beginning week in year $n$, stochastically given, and $T_{n}$ denote the last week of year $n$, definitely given.

We consider the interruptions between years as shown in Figure 1. Let $\tilde{\zeta}_{n}$ denote the length of interruption periods between year $n$ and $n+1$. We assume that the exact value of $\tilde{\zeta}_{n}$ is unknown for the owner and contractor before the year $n$ and determined 
stochastically after $T_{n}$ according to a probability distribution function $p\left(\tilde{\zeta}_{n}\right)$. We assume $p\left(\tilde{\zeta}_{n}\right)$ is an uniform distribution, i.e., $\tilde{\zeta}_{n} \sim U\left(\bar{\zeta}_{n}-\sigma, \bar{\zeta}_{n}+\sigma\right)$, and it satisfies:

$$
\int_{\bar{\zeta}_{n}-\sigma}^{\bar{\zeta}_{n}+\sigma} p\left(\zeta_{n}\right) d \zeta_{n}=1, \quad n=1,2, \cdots, N
$$

where $\bar{\zeta}_{n}$ is the mean value of the probability distribution $U\left(\bar{\zeta}_{n}-\sigma, \bar{\zeta}_{n}+\sigma\right)$. Since the $(n+1)$ th year begins after the interruption, the beginning period is also determined stochastically and is given by

$$
\tilde{t}_{n+1}=T_{n}+\tilde{\zeta}_{n}, \quad n=1,2, \cdots, N-1
$$

It can be said that $\tilde{t}_{n+1}$ also follows the uniform distribution, because $T_{n}$ is a deterministic parameter. Accordingly, it can be denoted as $\tilde{t}_{n} \sim U\left(\bar{t}_{n}-\sigma, \bar{t}_{n}+\sigma\right)$, where $\bar{t}_{n}$ is the mean value of $\tilde{t}_{n}$, and it is given by $\bar{t}_{n}=T_{n}+\bar{\zeta}_{n}$.

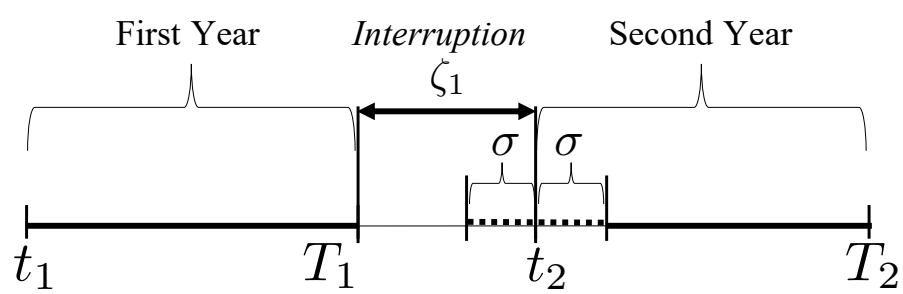

Figure 1. A discrete-continuous setting $(N=2)$.

We assume that this project is completely suspended during the interruption periods, and so the following equation holds:

$$
x\left(\tilde{t}_{n+1}\right)=x\left(T_{n}\right), \quad n=1,2, \cdots, N-1
$$

It means that the accumulated work does not deteriorate during the interruption periods.

Suppose that the contractor plans to allocate work effort $w(t)$ to each time period and that the progress of this project is described by $x(t)$, that is, the accumulation of $w(t)$. This dynamical system can be formulated as follows:

$$
\dot{x}(t)=w(t), \quad \forall t \in\left[t_{n}, T_{n}\right], n=1, \cdots, N
$$

where, $\dot{x}(t)=d x(t) / d t$.

Suppose the contractor receives the reward according to the quality of the outcome after the project. The quality of the outcome can be evaluated by the accumulated work effort at the completion time, $x\left(T_{N}\right)$. Let $\theta_{N}$ represent the monetary value of unit $x(t)$ and $\theta_{N} x\left(T_{N}\right)$ represent the reward evaluated in monetary terms. The contractor assigns work to each week by considering the reward $\theta_{N} x\left(T_{N}\right)$ as given. Let $C(w(t))$ represent the cost of work $w(t)$ at period $t$ in each year. We assume the following specific cost function:

$$
C(w(t))=f+\frac{c}{2} w(t)^{2}, \quad \forall t \in\left[\tilde{t}_{n}, T_{n}\right], n=1, \cdots, N
$$

where $f$ is a non-negative constant parameter representing the fixed costs and $c$ is a positive constant parameter. This cost function assumes that the contractor is required to expend some fixed costs $f$ to retain resources, such as workers, regardless of the amount of the work effort. Such a quadratic cost function is also assumed in Zhu et al. [21] and it is often used in economic analysis to describe the increase in the per-unit cost as the volume of effort increases.

We assume that the contractor determines the optimal allocation of work effort at the beginning of this project by considering the expected profit. Since the contractor considers 
the reward $\theta_{N}$ as given, the profit maximization problem of the $N$-year project can be formulated as

$$
\max E\left[J\left(x\left(t_{1}\right), \tilde{\mathbf{t}}_{1}, \mathbf{T}_{1}\right)\right]=E\left[e^{-r T_{N}} \theta_{N} x\left(T_{N}\right)-\sum_{n=1}^{N} \int_{\tilde{t}_{n}}^{T_{n}} e^{-r t} C(w(t)) d t\right]
$$

subject to Equations (3) and (4). Let $\mathbf{t}_{n}$ and $\mathbf{T}_{n}$ denote the set of the beginning and the end of each year from $n$th to $N$ th year, i.e., $=\tilde{\mathbf{t}}_{n} \in\left[\tilde{t}_{n}, \tilde{t}_{n+1}, \cdots, \tilde{t}_{N}\right]$ and $\mathbf{T} \in\left[T_{n}, T_{n+1}, \cdots, T_{N}\right]$, respectively. And $E[\cdot]$ denotes the expectation operator, defined as

$$
E[z(\tau)]=\int_{\bar{t}_{n}-\sigma}^{\bar{t}_{n}+\sigma} p(\tau) z(\tau) d \tau
$$

The work effort $w(t)$ is only defined in $\left\{t \mid \forall t \in\left[t_{n}, T_{n}\right], n=1, \cdots N\right\}$. We implicitly assume that $w(t)=0$ during the interruption periods by considering Equations (3) and (4).

\subsubsection{Optimal Decision of the Contractor}

The contractor is required to complete the project by the end of the $N$ th year $T_{N}$. We apply the backward induction ([24,25]) to obtain the optimal solution of the maximization problem, defined by Equations (3), (4) and (6). Suppose that the $N$ th year begins at $\tilde{t}_{N}$, the profit maximization problem of the $N$ th year, i.e., $t \in\left[\tilde{t}_{N}, T_{N}\right]$, is given by

$$
\max J\left(x\left(T_{N-1}\right), \tilde{t}_{N}, T_{N}\right)=e^{-r T_{N}} \theta_{N} x\left(T_{N}\right)-\int_{\tilde{t}_{N}}^{T_{N}} e^{-r t} C(w(t)) d t
$$

subject to

$$
\begin{gathered}
\dot{x}(t)=w(t), \quad \forall t \in\left[\tilde{t}_{N}, T_{N}\right] \\
x\left(\tilde{t}_{N}\right)=x\left(T_{N-1}\right)
\end{gathered}
$$

This optimization problem has the Hamiltonian

$$
H\left(x(t), w(t), \lambda_{N}(t)\right)=-e^{-r t}\left(f+\frac{c}{2} w(t)^{2}\right)+\lambda_{N}(t) \dot{x}(t)
$$

and its adjoint equation becomes

$$
\dot{\lambda}_{N}=-\frac{\partial H\left(x(t), w(t), \lambda_{N}(t)\right)}{\partial x(t)}=0
$$

This equation shows that $\lambda_{N}(t)$ is constant with respect to time. Thus, we write $\lambda_{N}(t)$ as $\lambda_{N}$ and determine its value through the boundary condition defined as

$$
\lambda_{N}=\frac{\partial J\left(T_{N}, T_{N}\right)}{\partial x\left(T_{N}\right)}=-\theta_{N} e^{-r T_{N}}
$$

The necessary condition for the optimal amount of work effort in each week is given by

$$
\frac{\partial H\left(x(t), w(t), \lambda_{N}(t)\right)}{\partial w(t)}=-e^{-r t} c w(t)+\lambda_{N}=0
$$

and the optimal solution can be obtained as

$$
\begin{gathered}
w^{*}(t)=\frac{\theta_{N}}{c} e^{r\left(t_{N}-T_{N}\right)} \quad \forall t \in\left[t_{N}, T_{N}\right] \\
x^{*}(t)=x\left(T_{N-1}\right)+\frac{\theta_{N} e^{-r T_{N}}}{c r}\left(e^{r t}-e^{r \tilde{t}_{N}}\right), \quad \forall t \in\left[\tilde{t}_{N}, T_{N}\right]
\end{gathered}
$$


where the first term is given by the Equation (3) $x\left(T_{N-1}\right)=x\left(\tilde{t}_{N}\right)$. Let $J^{*}\left(x\left(T_{N-1}\right), \tilde{t}_{N}, T_{N}\right)$ denote the profit function under the optimal control $w^{*}(t)$ and $x^{*}(t)$. We assume that $\tilde{t}_{N}$ is determined stochastically following the probability density function defined in Equation (1). The profit maximization problem of the $N-1$ year can be formulated as,

$$
\min J\left(x\left(T_{N-2}\right), \tilde{\mathbf{t}}_{N-1}, \mathbf{T}_{N-1}\right)=-\int_{\tilde{t}_{N-1}}^{T_{N-1}} e^{-r t} C(w(t))+E\left[J^{*}\left(x\left(T_{N-1}\right), \tilde{t}_{N}, T_{N}\right)\right]
$$

subject to Equation (4). The Hamiltonian for this problem can be formulated as Equation (11), and its boundary condition for the $(N-1)$ th year is given by

$$
\frac{\partial}{\partial x\left(T_{N-1}\right)} E\left[J^{*}\left(x\left(T_{N-1}\right), \tilde{t}_{N}, T_{N}\right)\right]=\theta_{2} e^{-r T_{2}}
$$

and its adjoint condition also becomes,

$$
\dot{\lambda}_{N-1}=0
$$

Therefore, the optimal control can be obtained as,

$$
w^{*}(t)=\frac{\theta_{N}}{c} e^{r\left(t-T_{N}\right)}, \quad \forall t \in\left[\tilde{t}_{N-1}, T_{N-1}\right] \text { and }\left[\tilde{t}_{N}, T_{N}\right]
$$

and

$$
x^{*}(t)=\left\{\begin{array}{lr}
x\left(T_{N-2}\right)+\frac{\theta_{N} e^{-r T_{N}}}{c r}\left(e^{r t}-e^{r \tilde{t}_{N-1}}\right), \quad \forall t \in\left[\tilde{t}_{N-1}, T_{N-1}\right] \\
x\left(T_{N-2}\right)+\frac{\theta_{N} e^{-r T_{N}}}{c r}\left(e^{r T_{N-1}}-e^{r \tilde{t}_{N-1}}+e^{r t}-e^{r \tilde{t}_{N}}\right), \quad \forall t \in\left[\tilde{t}_{N}, T_{N}\right]
\end{array}\right.
$$

We can obtain the optimal control $w^{*}(t), x^{*}(t)$ of all years, and also $J^{*}\left(x\left(t_{1}\right), \mathbf{t}, \mathbf{T}\right)$, by repeating these procedure to the first year $N=1$.

\subsection{Behavior of the Owner under Discrete-Continuous Multi-Period Setting}

\subsubsection{Benefit Function of the Owner}

The owner considers $v_{0}$ as the unit value of this project and pays the reward to the contractor at the completion time, $T_{N}$. The owner determines the reward per unit $\left(\theta_{N}\right)$ to maximize the net benefit by considering the contractor's response to the changes in $\theta_{N}$. Therefore, the optimal decision of the owner about $\theta_{N}$ in $N$-year project can be obtained by solving the following expected benefit maximization problem with respect to $\theta_{N}$ :

$$
E\left[V_{N}\left(\theta_{N}\right)\right]=\max \left(v_{0}-\theta_{N}\right) E\left[x^{*}\left(T_{N}, \theta_{N}\right)\right] e^{-r T_{N}}+\int_{T_{N}}^{\infty} e^{-(r+\delta) \tau} v_{0} E\left[x^{*}\left(T_{N}, \theta_{N}\right)\right] d \tau
$$

Because the owner considers the contractor's response to $\theta_{N}$, the amount of work effort at the completion time $T_{N}$ is also considered as a function of $\theta_{N}$, i.e., $E\left[x^{*}\left(T_{n}, \theta_{n}\right)\right]$. The first term of Equation (22) represents the net benefit at the completion time. The owner's net benefit per unit is given by the difference between the unit value $v_{0}$ and the unit reward to the contractor $\theta_{n}$. The second term represents the long-term benefit of this project. Although the benefit can be obtained after completion time to infinite time, the project value will decrease according to time. We assume the reduction of the project value is given by an exponential function, and the deterioration rate is given by a nonnegative parameter $\delta$. The optimization problem defined in Equation (22) can be simply rewritten as follows:

$$
E\left[V_{N}\left(\theta_{N}\right)\right]=\max \left(v-\theta_{N}\right) E\left[x^{*}\left(T_{N}, \theta_{N}\right)\right] e^{-r T_{N}}
$$


where,

$$
v=\left(1+\frac{1}{r+\delta}\right) v_{0}
$$

\subsubsection{Optimal Decision of the Owner}

The optimal decision of the owner can be obtained from the necessary condition for optimality of Equation (23). Hence, the condition becomes

$$
\left(v-\theta_{N}\right) \frac{\partial E\left[x^{*}\left(T_{N}, \theta_{N}\right)\right]}{\partial \theta_{N}} e^{-r T_{N}}-E\left[x^{*}\left(T_{N}, \theta_{N}\right)\right] e^{-r T_{N}}=0
$$

The optimal reward can be determined so as to satisfy this condition.

\subsubsection{Project Selection Rule of the Owner}

Suppose the owner can select the year of the project to maximize the owner's expected benefit. Let $V_{N}^{*}$ denote the optimal benefit function, i.e., $V_{N}\left(\theta_{N}^{*}\right)$, where $\theta_{N}^{*}$ is the optimal reward which satisfies the necessary condition, Equation (24). The owner's selection for the project year $N$ can be obtained from the problem given by

$$
N^{*}=\operatorname{argmax}_{n}\left\{V_{1}^{*}, E\left[V_{2}^{*}\right], \cdots, E\left[V_{n}^{*}\right], \cdots, E\left[V_{N}^{*}\right]\right\}
$$

Since we assume that $t_{1}$ is deterministically determined, i.e., $t_{1}=0, V_{1}^{*}$ has a deterministic value.

\section{Case Study: One-Year and Two-Year Project $(N=2)$}

We consider that the owner considers ordering a one-year or two-year project. First, we examine the optimal decisions of the owner and contractor under the existence of interruption between the first and the second years in a two-year project. Second, we consider those of a one-year project and examine the project selection [preference] of the owner [contractor] by comparing the benefits [profits] of each project. Here, we assume this project begins at $t_{1}=0$ and $x\left(t_{1}\right)=0$.

\subsection{Optimal Decisions under Two-Year Project}

When the contractor is required to complete the project within two years $(N=2)$. Since the optimal solution can be obtained from Equations (20) and (21), the optimal amount of work effort at the completion time $T_{2}$ can be obtained as

$$
E\left[x_{2}^{*}\left(T_{2}\right)\right]=\frac{\theta_{2} e^{-r T_{2}}}{c r}\left\{e^{r T_{1}}-1+e^{r T_{2}}-e^{r \bar{t}_{2}} \Phi(\sigma)\right\}
$$

where,

$$
\Phi(\sigma)=\frac{e^{r \sigma}-e^{-r \sigma}}{2 r \sigma}
$$

We can see that the amount of work effort is increasing with the increase in the unit reward $\theta_{2}$ and the decrease in the unit $\operatorname{cost} c$. We can also observe that the increase in the expected beginning period of the second year decreases $E\left[x_{2}^{*}\left(T_{2}\right)\right]$. In other words, the increase in the expected length of the interruption decreases the amount of work effort. $\Phi(\sigma)$ is a function of the variance of $\tilde{t}_{2}$, and satisfies the properties which are shown in the following lemma

\section{Lemma 1.}

(i) $\Phi(\sigma)$ increases with the increase in the variance of the length of interruption periods $\sigma$, i.e.,

$$
\frac{d \Phi(\sigma)}{d \sigma}>0
$$


(ii) The value of $\Phi(\sigma)$ has the lower and upper bound, such as,

$$
1 \leq \Phi(\sigma) \leq \frac{e^{r \sigma}+e^{-r \sigma}}{2} \leq \frac{e^{r\left(\bar{t}_{2}-T_{1}\right)}+e^{-r\left(\bar{t}_{2}-T_{1}\right)}}{2}
$$

Proof of Lemma 1. See Appendix A.

It can be said that the total amount of work effort of the two-year project decreases with the increase in the variance of the interruption period from the Lemma 1.

Now, we have the optimal response function of the contractor with respect to $\theta_{2}$ by considering the discussion in the previous section. The optimal reward can be obtained as,

$$
\theta_{2}^{*}=\frac{v}{2}
$$

from the condition, Equation (24). The expected benefit of the owner with the optimal reward can be obtained as,

$$
E\left[V_{2}^{*}\left(T_{2}\right)\right]=\frac{v^{2} e^{-2 r T_{2}}}{4 c r}\left(e^{r T_{2}}-1\right)+\frac{v^{2} e^{-2 r T_{2}}}{4 c r}\left(e^{r T_{1}}-e^{r \bar{t}_{2}} \Phi(\sigma)\right)
$$

The first term in Equation (31) represents the benefit without interruption, which is the benefit of the two-year project can continue without interruption from period 0 to $T_{2}$. The second term is always non-positive, because $\bar{t}_{2} \geq T_{1}$ and $\Phi(\sigma) \geq 1$ from Equation (29) of Lemma 1. It represents that the existence of the interruption periods decreases the owner's expected benefit. It can be summarized that the properties of the expected benefit for the interruption periods, as the following Proposition 1.

\section{Proposition 1.}

(i) The expected benefit of the owner is decreased by the existence of interruption periods.

(ii) The increase in the expected interruption length decreases the expected benefit of the twoyear project.

(iii) The increase in the variance of the interruption length decreases the expected benefit of the two-year project.

Proof of Proposition 1. See Appendix A.

It follows from $e^{r T_{2}}>e^{r \bar{t}_{2}} \Phi(\sigma)$ and $e^{r T_{1}}>1$ that Equation (31) has non-negative value, i.e., $E\left[V_{2}^{*}\left(T_{2}\right)\right] \geq 0$. Thus, the owner expects positive benefit by selecting two-year project.

As the result of the optimal decision by the owner, the expected amount of work for the two-year project can be obtained as

$$
E\left[x_{2}^{*}\left(T_{2}\right)\right]=\frac{v e^{-r T_{2}}}{2 c r}\left\{e^{r T_{2}}-1+\left(e^{r T_{1}}-e^{r \bar{t}_{2}} \Phi(\sigma)\right)\right\}
$$

From this equation, we can observe that the total amount of work is decreased by the existence of interruption because the second term in parentheses becomes negative under the conditions of $T_{1} \leq \bar{t}_{2}$ and $\Phi(\sigma)>1$. It can also be obtained that the expected profit of the contractor under the optimal reward as

$$
\begin{aligned}
E\left[J_{2}^{*}\left(0, \tilde{\mathbf{t}}_{1}, \mathbf{T}_{1}\right)\right]= & \frac{v^{2} e^{-2 r T_{2}}}{8 c r}\left(e^{r T_{2}}-1\right)-\frac{f}{r}\left(1-e^{-r T_{2}}\right) \\
& -\frac{v^{2} e^{-2 r T_{2}}}{8 c r}\left(e^{r \bar{t}_{2}} \Phi(\sigma)-e^{r T_{1}}\right)+\frac{f}{r}\left(e^{-r T_{1}}-e^{-r \bar{t}_{2}} \Phi(\sigma)\right)
\end{aligned}
$$

The impact of the interruption on the expected profit can be seen in the third and fourth terms of Equation (33). The third term represents the decrease in the expected profit due to the existence of the interruption period. And the fourth term represents the increase 
in the expected profit due to the decrease in the fixed cost by suspending the project during the interruption. Thus, the increase or decrease in the expected profit depends on the relative size of the project value $v$ and the fixed cost $f$. Proposition 2 summarizes the properties of the expected profit, $E\left[J_{2}^{*}\left(0, \tilde{\mathbf{t}}_{1}, \mathbf{T}_{1}\right)\right]$.

\section{Proposition 2.}

(i) The expected profit of the contractor is increased [decreased] by the existence of interruption if the project value $v$ is sufficiently larger [smaller] than the fixed cost $f$.

(ii) The expected profit of the contractor is increased [decreased] with the increase in the expected length of interruption if the project value $v$ is sufficiently larger [smaller] than the fixed cost $f$.

(iii) The expected profit of the contractor is always decreasing with the increase in the variance of interruption length.

Proof of Proposition 2. See Appendix A.

In order to implement the two-year project, the expected profit must be greater than or equal to zero. Proposition 2 suggests that projects that are expected to obtain larger profits due to their large project value will be less attractive by becoming interruption length longer or increasing uncertainty.

\subsection{Comparison between Projects}

Optimal Decision under One-Year Project $(N=1)$

Suppose that the contractor is required to complete the project by the end of the first year, $T_{1}$. The optimal decision of the contractor is then determined by the following deterministic optimization problem:

$$
\min J\left(x\left(t_{1}\right), t_{1}, T_{1}\right) \equiv e^{-r T_{1}} \theta_{1} x\left(T_{1}\right)-\int_{t_{1}}^{T_{1}} e^{-r t} C_{1}(w(t)) d t
$$

subject to

$$
\dot{x}(t)=w(t), \quad \forall t \in\left[0, T_{1}\right]
$$

where we assume that $t_{1}=0$ and $x\left(t_{1}\right)=0$. The optimal control can be obtained by following a similar procedure in the two-year project, yielding

$$
w^{*}(t)=\operatorname{argmax} H\left(x_{1}(t), w_{1}(t), \lambda_{1}(t)\right)=\frac{\theta_{1}}{c} e^{r\left(t-T_{1}\right)} \quad \forall t \in\left[0, T_{1}\right]
$$

This function shows that the optimal amount of work in each week will increase with time $t$. This is because the cost per unit of work can be discounted by the time discount rate. However, as the completion time $T_{1}$ becomes longer, the amount of work in each week becomes smaller. This is because the manager can allocate work to more weeks.

As the result of allocating work in each week according to Equation (36), the project quality achieved at $T_{1}$ becomes

$$
x^{*}\left(T_{1}\right)=\frac{\theta_{1}}{c r}\left(1-e^{-r T_{1}}\right)
$$

The project quality $x_{1}^{*}\left(T_{1}\right)$ increases as the value of $\theta_{1}$ increases. In contrast, increases in the cost of work $c_{1}$ and the time discount rate reduce the project quality. This is because the benefit of this project is only generated at the completion time $T_{1}$, and any increase in the time discount rate lowers the present value of the project. Therefore, an increase in the time discount rate decreases the project quality. 
We can derive the optimal amount of work under the optimal reward, by considering the optimal reward which can be derived from Equation (24) and the optimal amount of work Equation (37).

$$
x_{1}^{*}=\frac{v}{2 c r}\left(1-e^{-r T_{1}}\right)
$$

And we can also derive the profit of the contractor under the optimal decisions as follows:

$$
J_{1}^{*}\left(0, t_{1}, T_{1}\right)=\frac{v^{2} e^{-2 r T_{1}}}{8 c r}\left(e^{r T_{1}}-1\right)-\frac{f}{r}\left(1-e^{-r T_{1}}\right)
$$

The owner's benefit in the one-year project can be obtained by considering $x_{1}^{*}$ into the net benefit function defined by Equation (23).

$$
V_{1}^{*}\left(T_{1}\right)=\frac{v^{2} e^{-r T_{1}}}{4 c r}\left(1-e^{-r T_{1}}\right)
$$

Equation (40) represents that the $V_{1}^{*}\left(T_{1}\right)$ has non-negative value, i.e., $V_{1}^{*}\left(T_{1}\right) \geq 0$, because $T_{1}>0$ and $v \geq 0$. Thus, the owner can obtain positive benefit by selecting one-year project. This paper only considers exogenously determined completion time, $T_{1}$ and $T_{2}$. The relationship between the completion time and the net benefit function can be obtained as shown in the following lemma,

Lemma 2. There exists an optimal completion time that maximizes $V_{1}^{*}\left(T_{1}\right)$,

$$
\frac{d V_{1}^{*}\left(T_{1}\right)}{d T_{1}}= \begin{cases}\geq 0, & \text { if } T_{1} \leq \frac{\ln (2)}{r} \\ <0, & \text { if } T_{1}>\frac{\ln (2)}{r}\end{cases}
$$

and there also exists an optimal completion time that maximizes $E\left[V_{2}^{*}\left(T_{2}\right)\right]$,

$$
\frac{d E\left[V_{2}^{*}\left(T_{2}\right)\right]}{d T_{2}}=\left\{\begin{array}{ll}
\geq 0, & \text { if } T_{2} \leq \frac{1}{r}\left\{\ln (2)+\ln \left(e^{r \bar{t}_{2}} \Phi(\sigma)-e^{r T_{1}}+1\right.\right. \\
<0, & \text { if } T_{2}>\frac{1}{r}\left\{\ln (2)+\ln \left(e^{r \bar{t}_{2}} \Phi(\sigma)-e^{r T_{1}}+1\right.\right.
\end{array}\right\}
$$

Lemma 2 implies that if the project duration is sufficiently long, it decreases the net benefit by setting the duration longer.

\subsection{Project Selection by the Owner}

We now discuss the owner's selection between the one-year and two-year projects. The owner selects one of the projects by following the rule given by Equation (25). In this case, it can be rewritten as follows,

$$
N^{*}= \begin{cases}1, & \Delta E\left[V^{*}\right] \leq 0 \\ 2, & \Delta E\left[V^{*}\right]>0\end{cases}
$$

where,

$$
\begin{aligned}
& \Delta E\left[V^{*}\right]=E\left[V_{2}^{*}\left(T_{2}\right)\right]-V_{1}^{*}\left(T_{1}\right) \\
& \quad=\frac{v}{4 c r}\left\{e^{-2 r T_{2}}\left(e^{r T_{1}}-1+e^{r T_{2}}-e^{r \bar{t}_{2}} \Phi(\sigma)\right)-e^{-2 r T_{1}}\left(e^{r T_{1}}-1\right)\right\}
\end{aligned}
$$

The following proposition represents the differences in the projects selected by the owner, according to the expected length of the interruption. 


\section{Proposition 3.}

(i) The owner selects the two-year project, if the interruption length is sufficiently shorter, i.e., $\bar{\zeta}_{1}<\zeta_{\left[E\left[V_{2}^{*}\right]=V_{1}^{*}\right]}$.

(ii) The owner selects ones-year project, if the interruption length is sufficiently longer, i.e., $\bar{\zeta}_{1}>\zeta_{\left[E\left[V_{2}^{*}\right]=V_{1}^{*}\right]}$.

where,

$$
\zeta_{\left[E\left[V_{2}^{*}\right]=V_{1}^{*}\right]}=\frac{1}{r}\left\{\ln \left\{e^{r T_{2}}-\left(e^{2 r\left(T_{2}-T_{1}\right)}-1\right)\left(e^{r T_{1}}-1\right)\right\}-\ln \Phi(\sigma)\right\}-T_{1}
$$

Proof of Proposition 3. See Appendix A.

The amount of work effort is also affected by the interruption. Let $E\left[\Delta x^{*}\right]$ denote the difference between those of projects and it is defined as

$$
\begin{aligned}
\Delta E\left[x^{*}\right] & =E\left[x_{2}^{*}\left(T_{2}\right)\right]-x_{1}^{*}\left(T_{1}\right) \\
& =\frac{v}{2 c r}\left\{e^{-r T_{2}}\left(e^{r T_{1}}-1+e^{r T_{2}}-e^{r \bar{t}_{2}} \Phi(\sigma)\right)-e^{-r T_{1}}\left(e^{r T_{1}}-1\right)\right\}
\end{aligned}
$$

The following proposition represents the properties of the amount of work effort, according to the selected project.

\section{Proposition 4.}

(i) When the owner selects the two-year project, the amount of work effort of the two-year project is always larger than that of the one-year project.

(ii) When the owner selects the one-year project,

(a) the amount of work effort of the one-year project is larger than that of the two-year project, if the interruption period is longer than $\zeta_{\left[E\left[x_{2}^{*}\right]=x_{1}^{*}\right]}$, i.e., $\bar{\zeta}_{1}>\zeta_{\left[E\left[x_{2}^{*}\right]=x_{1}^{*}\right]}$.

(b) the amount of work effort of the one-year project is smaller than that of the two-year project, if the interruption period is shorter than $\zeta_{\left[E\left[x_{2}^{*}\right]=x_{1}^{*}\right]}$, i.e., $\bar{\zeta}_{1}<\zeta_{\left[E\left[x_{2}^{*}\right]=x_{1}^{*}\right]}$.

where,

$$
\zeta_{\left[E\left[x_{2}^{*}\right]=x_{1}^{*}\right]}=\frac{1}{r}\left\{\ln \left(e^{r\left(T_{2}-T_{1}\right)}+e^{r T_{1}}-1\right)-\ln \Phi(\sigma)\right\}-T_{1}
$$

and $\zeta_{\left[E\left[x_{2}^{*}\right]=x_{1}^{*}\right]} \geq \zeta_{\left[E\left[V_{2}^{*}\right]=V_{1}^{*}\right]}$.

Proof of Proposition 4. See Appendix A.

Figure 2 summarizes the Propositions 3 and 4 in the deterministic case $(\sigma=0) . T_{2}$ must be larger than $T_{1}+\bar{\zeta}_{1}$ for consistency, only upper-left side of the Figure 2 can be considered. Since $\zeta_{\left[E\left[x_{2}^{*}\right]=x_{1}^{*}\right]} \geq \zeta_{\left[E\left[V_{2}^{*}\right]=V_{1}^{*}\right]}$, the threshold value $\zeta_{\left[E\left[V_{2}^{*}\right]=V_{1}^{*}\right]}$ is always located on the left-hand side of $\zeta_{\left[E\left[x_{2}^{*}\right]=x_{1}^{*}\right]}$. Thus, when the interruption length $\bar{\zeta}_{1}$ is shorter than $\zeta_{\left[E\left[V_{2}^{*}\right]=V_{1}^{*}\right]}$, the owner selects the two-year project and the resulted amount of work effort is larger than that of the one-year project. On the other hand, if $\zeta_{\left[E\left[V_{2}^{*}\right]=V_{1}^{*}\right]}<\bar{\zeta}_{1}<\zeta_{\left[E\left[x_{2}^{*}\right]=x_{1}^{*}\right]}$ holds, even though the amount of work effort is larger for the one-year project, the two-year project is ordered. Furthermore, the longer the interruption length, the less duration is available for the two-year project, so the one-year project is selected, and the resulted amount of work effort is larger than that of the two-year project. 


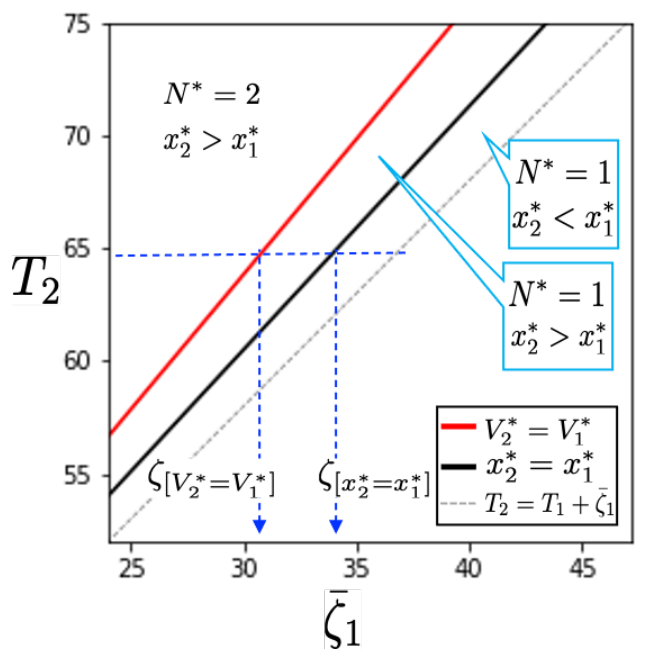

Figure 2. Owner's decision in the deterministic case $(\sigma=0$ (weeks)).

The threshold values defined in Equations (45) and (47) are affected by the variance of interruption length $\sigma$. The following proposition can be derived and it implies that the conditions under which the two-year project is selected vary with uncertainty in the interruption.

Proposition 5. As the variance of the interruption length increases, the threshold value of selecting the two-year project becomes smaller, i.e., $\frac{d \zeta_{\left[E\left[V_{2}^{*}\right]=V_{1}^{*}\right]}}{d \sigma}<0$. And the threshold value of characterizing

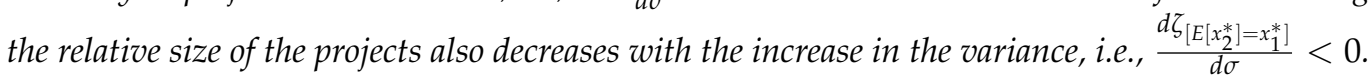

Proof of Proposition 5. See Appendix A.

Proposition 5 represents that the allowable interruption length to select the two-year project becomes smaller with the increase in the variance of interruption length. It suggests that long-term projects might be more difficult to be ordered under conditions where global warming increases uncertainty in the interruption.

Figure 3 is a graphical representation of Proposition 5, which represents the impact of interruption on $\zeta_{\left[E\left[V_{2}^{*}\right]=V_{1}^{*}\right]}$ and $\zeta_{\left[E\left[x_{2}^{*}\right]=x_{1}^{*}\right]}$. (See Appendix A for the numerical setting.) The dotted lines in Figure 3 show the $\zeta_{\left[E\left[V_{2}^{*}\right]=V_{1}^{*}\right]}$ and $\zeta_{\left[E\left[x_{2}^{*}\right]=x_{1}^{*}\right]}$ under the deterministic case, which are shown in Figure 2. We can see that these threshold values are shifted to the left-hand side. This suggests that as the uncertainty of the interruption period increases, the owner will order a two-year project when the interruption period is shorter.

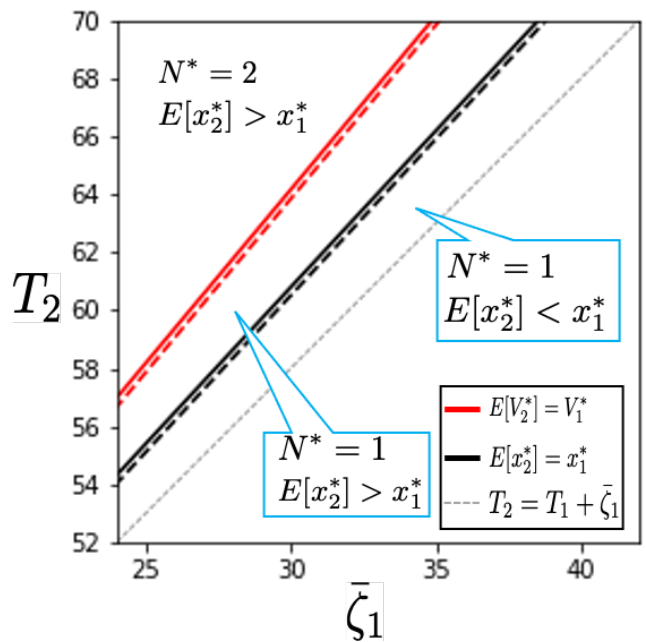

Figure 3. Owner's decision in the stochastic case $(\sigma=24$ (weeks)). 
As the uncertainty in interruption periods changes, the owner's benefit also changes. The variance of the owner's benefit can be defined as

$$
\begin{gathered}
\operatorname{Var}\left[V_{2}^{*}\left(T_{2}\right)\right]=\int_{\bar{t}_{2}-\sigma}^{\bar{t}_{2}+\sigma} \frac{\left.\left\{V_{2}^{*}\left(T_{2}\right)-E\left[V_{2}^{*}\left(T_{2}\right)\right]\right\}\right)^{2}}{2 \sigma} d \tilde{t}_{2} \\
=\frac{v^{4} e^{-4 r T_{2}}}{16 c^{2} r^{2} \sigma} \int_{\bar{t}_{2}-\sigma}^{\bar{t}_{2}+\sigma}\left\{e^{r \tilde{t}_{2}}-e^{r \bar{t}_{2}} \Phi(\sigma)\right\}^{2} d \tilde{t}_{2}
\end{gathered}
$$

Figure 4 shows the relationship between $\sigma$ and the benefits. This figure shows the case that the two-year project is selected by the owner because the expected benefit of the two-year project is larger than that of the one-year project, i.e., $E\left[V_{2}^{*}\left(T_{2}\right)\right]>V_{1}^{*}\left(T_{1}\right)$. We can see that the changes in $E\left[V_{2}^{*}\left(T_{2}\right)\right]$ is smaller than changes in $V_{2}^{*}\left(\bar{\zeta}_{1}-\sigma\right)$ and $V_{2}^{*}\left(\bar{\zeta}_{1}+\sigma\right)$, which show the resulting benefits after the interruption. $V_{2}^{*}\left(\bar{\zeta}_{1}-\sigma\right)$ represents the possible shortest interruption periods in the uniform distribution $\tilde{\zeta}_{1} \sim U\left(\bar{\zeta}_{1}-\sigma, \bar{\zeta}_{1}+\sigma\right)$. Under the shortest interruption case, the owner can obtain the largest benefit and it increases with the variance $\sigma$. On the other hand, $\left(\bar{\zeta}_{1}+\sigma\right)$ gives the longest interruption periods, it results the smallest benefit after $T_{2} \cdot V_{2}^{*}\left(\bar{\zeta}_{1}+\sigma\right)$ decreases with the increase in $\sigma$. And it is found that $V_{2}^{*}\left(\bar{\zeta}_{1}+\sigma\right)$ becomes lower than $V_{1}^{*}\left(T_{1}\right)$ in the case of large $\sigma$. In the symmetric uniform distribution considered here, the increase in uncertainty causes a small change in the expected benefit, but a large change in the resulting benefit might be smaller than that of the one-year project, even though the two-year project was selected because of its larger expected benefit.

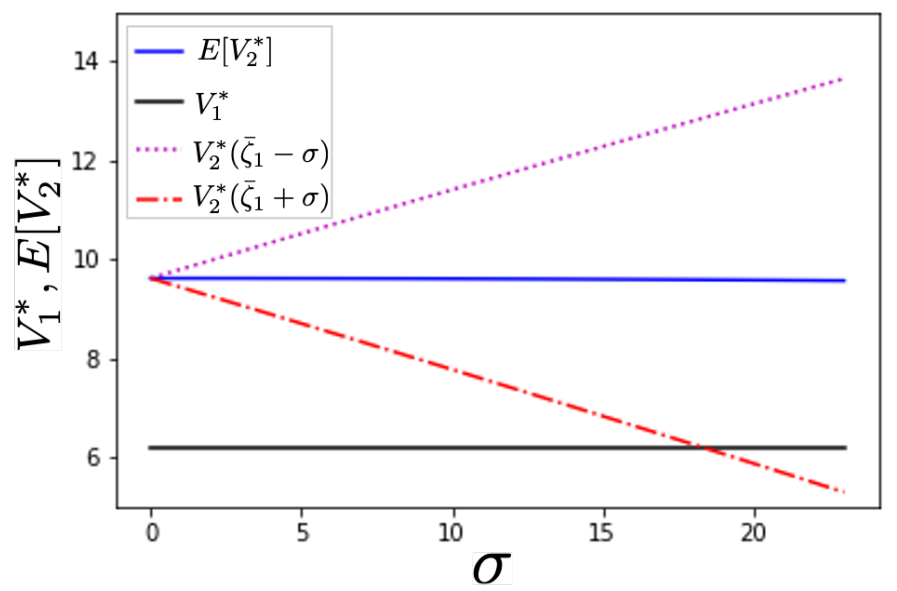

Figure 4. Changes in the owner's benefits with the changes in the variance of interruption length.

\subsection{Project Preference of the Contractor}

In this section, we compare the expected profits of the contractor obtained from each of the projects, to analyze the impact of the interruption on the contractor. We assume that the contractor prefers the project that can achieve a larger expected profit. The contractor's preference under the owner's order can be summarized as the following proposition.

\section{Proposition 6.}

(i) When the owner orders the one-year project and the project is implemented, the contractor preferred the one-year project than the two-year project, i.e., $\left.E\left[J_{2}^{*}\left(0, \tilde{\mathbf{t}}_{1}, \mathbf{T}_{1}\right)\right] \leq J_{1}^{*}\left(0, t_{1}, T_{1}\right)\right)$.

(ii) When the owner orders the two-year project and the project is implemented, the contractor preferred the two-year [one-year] project, if the project value $v$ is sufficiently larger [smaller] than the fixed cost $f$. 
Proof of Proposition 6. See Appendix A.

Proposition 6 (i) can be graphically represented as Figure 5. It represents the stochastic interruption with $\sigma=36$ (weeks). First, the condition of implementing the one-year project is given by the area on the upper side of $v_{\left[J_{1}^{*}=0\right]}$. The contractor prefers the one-year project, regardless of its project value $v$, under the condition of $E\left[V_{2}^{*}\left(T_{2}\right)\right]<V_{1}^{*}\left(T_{1}\right)$. Therefore, if the one-year project is implemented, the contractor prefers the one-year project.

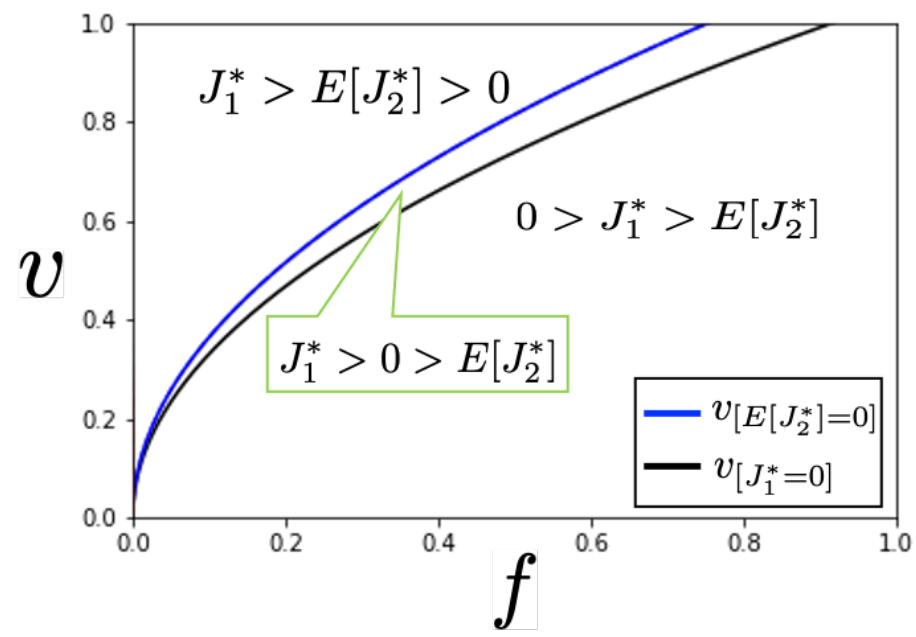

Figure 5. Contractor's preference when the owner orders the one-year project $\left(E\left[V_{2}^{*}\left(T_{2}\right)\right]<V_{1}^{*}\left(T_{1}\right)\right)$.

Proposition 6 (ii) can be graphically represented in Figure 6. First, the condition of implementing the two-year project is given by the area on the upper-left side of $v_{\left[E\left[J_{2}^{*}\right]=0\right]}$ (blue line). The contractor prefers the two-year project, if its project value $v$ is larger than $v_{\left[E\left[J_{2}^{*}\right]=J_{1}^{*}\right]}$. If the project value $v$ lies between $v_{\left[E\left[J_{2}^{*}\right]=0\right]}$ and $v_{\left[E\left[J_{2}^{*}\right]=J_{1}^{*}\right]}$, the two-year project will be ordered by the owner, even though the one-year project would be more preferable by the contractor. The grey dotted line shows the value of $v_{\left[E\left[J_{2}^{*}\right]=J_{1}^{*}\right]}$ in the deterministic case $\left(\sigma=0\right.$ (weeks)), we can see that $v_{\left[E\left[J_{2}^{*}\right]=J_{1}^{*}\right]}$ is increased by considering the variation of interruption length. It suggests that a larger project value is needed for the two-year project to be preferred by the contractor in the presence of uncertainty.

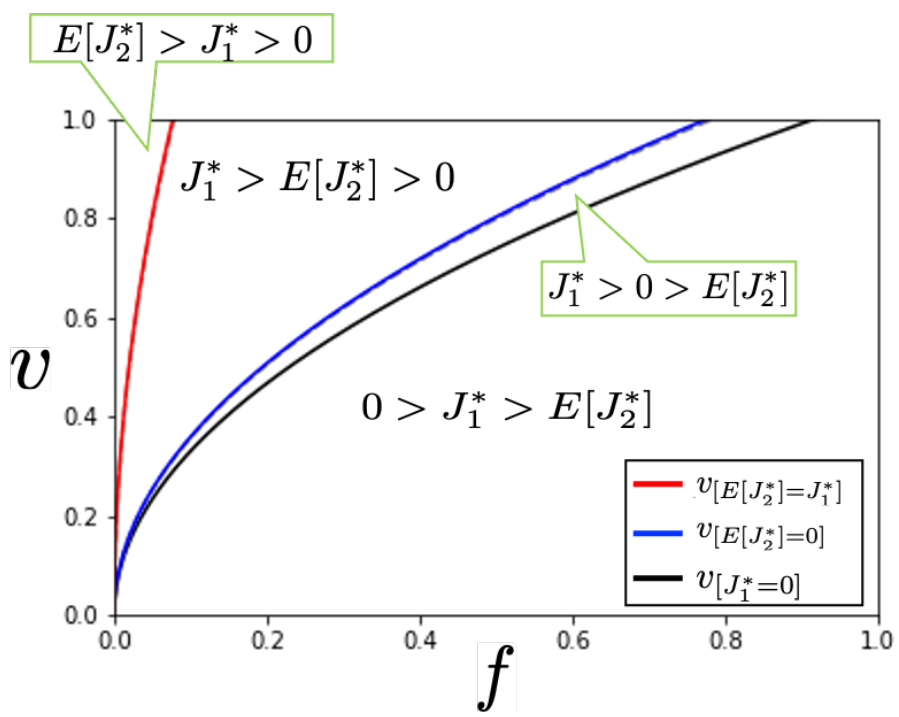

Figure 6. Contractor's preference when the owner orders the two-year project $\left(E\left[V_{2}^{*}\left(T_{2}\right)\right]>V_{1}^{*}\left(T_{1}\right)\right)$.

As the interruption length changes, the contractor's profit also changes. The variance of the contractor's profit can be given by 


$$
\begin{aligned}
\operatorname{Var}\left[J_{2}^{*}\left(0, \mathbf{t}_{1}, \mathbf{T}_{2}\right)\right]= & \int_{\bar{t}_{2}-\sigma}^{\bar{t}_{2}+\sigma} \frac{\left\{J_{2}^{*}\left(0, \mathbf{t}_{1}, \mathbf{T}_{2}\right)-E\left[J_{2}^{*}\left(0, \mathbf{t}_{1}, \mathbf{T}_{2}\right)\right]\right\}^{2}}{2 \sigma} d \tilde{t}_{2} \\
= & \frac{1}{4} \operatorname{Var}\left[V_{2}^{*}\left(T_{2}\right)\right]+\frac{f^{2}}{r^{2} \sigma} \int_{\bar{t}_{2}-\sigma}^{\bar{t}_{2}+\sigma}\left\{e^{-r \tilde{t}_{2}}-e^{-r \bar{t}_{2}} \Phi(\sigma)\right\}^{2} d \tilde{t}_{2} \\
& +\frac{f v^{2} e^{-2 r T_{2}}}{4 c r^{2} \sigma} \int_{\bar{t}_{2}-\sigma}^{\bar{t}_{2}+\sigma}\left\{e^{r \tilde{t}_{2}}-e^{r \bar{t}_{2}} \Phi(\sigma)\right\}\left\{e^{-r \tilde{t}_{2}}-e^{-r \bar{t}_{2}} \Phi(\sigma)\right\} d \tilde{t}_{2}
\end{aligned}
$$

Figure 7 shows the changes in the contractor's expected profit $E\left[J_{2}^{*}\left(0, \tilde{\mathbf{t}}_{1}, \mathbf{T}_{1}\right)\right]$ and resulting profits $J_{2}^{*}\left(\bar{\zeta}_{1}-\sigma\right)\left(=J_{2}^{*}\left(0, \bar{\zeta}_{1}-\sigma, \mathbf{T}_{1}\right)\right), J_{2}^{*}\left(\bar{\zeta}_{1}+\sigma\right)\left(=J_{2}^{*}\left(0, \bar{\zeta}_{1}+\sigma, \mathbf{T}_{1}\right)\right), J_{1}^{*}\left(0,0, T_{1}\right)$ under the various value of $\sigma$. Figure 7 is the case that the contractor prefers the two-year project, because $E\left[J_{2}^{*}\left(0, \tilde{\mathbf{t}}_{1}, \mathbf{T}_{1}\right)\right]>J_{1}^{*}\left(0,0, T_{1}\right)$. As the increase in $\sigma$, the smallest profit which is obtained in the longest interruption, i.e., in the case of $\bar{\zeta}_{1}+\sigma$, becomes smaller than $J_{1}^{*}\left(0,0, T_{1}\right)$. Therefore, as we have discussed the owner's benefit, it is suggested that the resulting profit of the two-year project may be lower than that of the one-year project, even though the two-year project was preferred by the contractor in terms of the expected profit. However, the preferred project by the contractor can be consistent with the selected project by decreasing the fixed costs $f$ relative to the benefit $v$. As shown in Figure 7 , decreasing the fixed costs decreases the difference of the contractor's profits between one-year and two-year projects and it can finally achieve a situation where the contractor prefers a two-year $\operatorname{project}\left(E\left[J_{2}^{*}\right]>J_{1}^{*}>0\right)$.

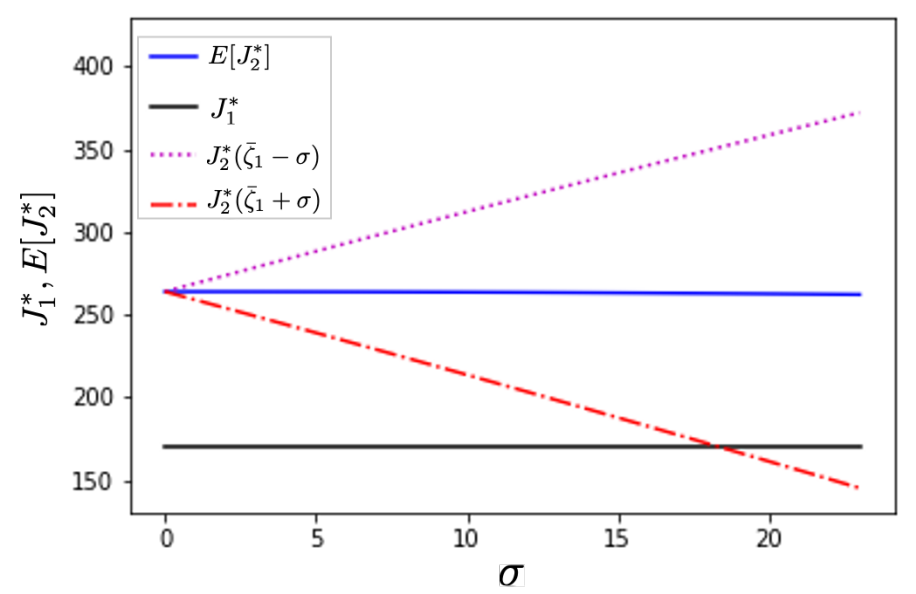

Figure 7. Changes in the contractor's profits with the changes in the variance of interruption length

\section{Conclusions}

In this study, we investigate the impact of interruption on the decision-making of the project owner and contractor theoretically. We find that as the interruption period becomes longer, the owner's profit always decreases, whereas the contractor's profit increases when the fixed cost is high relative to the fixed cost. In such a higher fixed cost case, it is also found that the contractor prefers the one-year project, even when the owner selects the two-year project. These results imply that the desirable project is different for owner and contractor and the conflict between the stakeholders is expected to occur under such a higher fixed cost condition. Our results suggest that such conflicts can be mitigated by introducing policies (e.g., subsidies and promotion of new technology adoption) that would lower the fixed costs of contractors and increase the profit of the two-year project.

We also represent the threshold values of the interruption length that determine the project selection by the owner and the relative quality of outcomes. It was found that there exists a range of expected interruption lengths that leads the owner to select the project with relatively lower quality. This study also shows that the increase in the variance of the interruption length decreases the thresholds and it makes it difficult for the owner to select the two-year project. This finding is consistent with Schwartz and 
Zozaya-Gorostiza [18], which showed the large uncertainty makes the project abandonment attractive by applying real options theory. Our study also finds a range of interruption lengths where the selected project does not provide the higher quality outcome, which is not mentioned in the previous study. Further empirical studies are recommended to promote a quantitative understanding of the likelihood of such differences with respect to the length and variability of the interruption period. Furthermore, we can often observe uncertain project interruption due to the spread of infectious diseases. We hope that this study helps to promote the understanding of such project interruption.

Author Contributions: Conceptualization, K.O. and M.O.; methodology, K.O.; software, K.O.; validation, K.O. and M.O.; formal analysis, K.O.and M.O.; investigation, K.O. and M.O.; resources, K.O. and M.O.; writing—original draft preparation, K.O.; writing—review and editing, K.O. and M.O.; visualization, K.O. and M.O.; supervision, M.O.; project administration, M.O.; funding acquisition, M.O. All authors have read and agreed to the published version of the manuscript.

Funding: This research received a Grant for CNEAS regular project from the Center for Northeast Asian Studies, Tohoku University.

Institutional Review Board Statement: Not applicable.

Informed Consent Statement: Not applicable.

Data Availability Statement: Not applicable.

Acknowledgments: The authors would like to acknowledge the support of a Grant for CNEAS regular project from the Center for Northeast Asian Studies, Tohoku University.

Conflicts of Interest: The authors declare no conflict of interest.

\section{Appendix A}

Appendix A.1. Proofs

Proof of Lemma 1. Differentiating $\Phi(\sigma)$ with respect to the variance $\sigma$, we have

$$
\frac{d \Phi}{d \sigma}=-\frac{r \sigma\left(e^{r \sigma}+e^{-r \sigma}\right)-\left(e^{r \sigma}-e^{-r \sigma}\right)}{2 r \sigma^{2}}>0
$$

As the inequalities shown in Plaza [26], the numerator of this equation becomes larger than zero. The first inequality in Equation (29) can be shown by using the inequality [26] such as,

$$
\Phi(\sigma)=\frac{e^{r \sigma}-e^{-r \sigma}}{2}>e^{e^{r \sigma}-e^{e^{r()}}-e^{-r \sigma}} 2=1
$$

The second inequality in Equation (29) can be derived directly from Plaza [26]. And the assumption that $T_{1}+\sigma \leq \bar{t}_{2}$ implies $\bar{t}_{2}-T_{1} \geq \sigma$. By considering the qualitative property of $\cosh (x)$ in $x>0$, the following inequality can be obtained as

$$
\frac{e^{r \sigma}+e^{-r \sigma}}{2}=\cosh (r \sigma) \leq \cosh \left(r\left(\bar{t}_{2}-T_{1}\right)\right)=\frac{e^{r\left(\bar{t}_{2}-T_{1}\right)}+e^{-r\left(\bar{t}_{2}-T_{1}\right)}}{2}
$$

Proof of Proposition 1. When the interruption exists, $\bar{t}_{2}$ is larger than $T_{1}$, i.e., $\bar{t}_{2}>T_{1}$. Thus, we can obtain Proposition 1 (i), because the second term of Equation (31) is negative from the conditions $\bar{t}_{2}>T_{1}$ and $\Phi(\sigma) \geq 1$ (Lemma 1). The increase in the expected interruption length is equivalent to the increase in the expected beginning period of the second year by considering Equation (2). We can obtain Proposition 1 (ii) by examining the response of $E\left[V_{2}^{*}\left(T_{2}\right)\right]$ with respect to $\bar{t}_{2}$ and it is given by,

$$
\frac{\partial E\left[V_{2}^{*}\left(T_{2}\right)\right]}{\partial \bar{t}_{2}}=-\frac{v^{2} e^{-2 r T_{2}}}{4 c} e^{r \bar{t}_{2}} \Phi(\sigma)<0
$$


Since $\Phi(\sigma)>1, E\left[V_{2}^{*}\left(T_{2}\right)\right]$ always decreases with the increase in $\bar{t}_{2}$. And the response of $E\left[V_{2}^{*}\left(T_{2}\right)\right]$ to the variance of the interruption length $\sigma$ is given by

$$
\frac{\partial E\left[V_{2}^{*}\left(T_{2}\right)\right]}{\partial \sigma}=-\frac{v^{2} e^{-2 r T_{2}}}{4 c r} e^{r \bar{t}_{2}} \frac{d \Phi(\sigma)}{d \sigma}<0
$$

The sign of this equation is negative from Lemma 1 (i). Thus, we can obtain Proposition 1 (iii).

Proof of Proposition 2. We can obtain Proposition 2 (i) by comparing the size of the third and fourth terms of Equation (33). The expected profit of the contractor is increased, if the project value satisfies the following condition:

$$
v \geq 2 e^{r T_{2}} \sqrt{2 c f \frac{e^{-r T_{1}}-e^{-r \bar{t}_{2}} \Phi(\sigma)}{e^{r \bar{t}_{2}} \Phi(\sigma)-e^{r T_{1}}}}
$$

And otherwise, the expected profit of the contractor is decreased by the existence of interruption, i.e., $\bar{t}_{2}>T_{1}$. Since the increase in the expected interruption length is described by the increase in $\bar{t}_{2}$, the differentiation of $E\left[V_{2}^{*}\left(T_{2}\right)\right]$ with respect to $\bar{t}_{2}$ becomes

$$
\frac{\partial E\left[J_{2}^{*}\left(0, \tilde{\mathbf{t}}_{1}, \mathbf{T}_{1}\right)\right]}{\partial \bar{t}_{2}}=\left(f-\frac{v^{2} e^{-2 r\left(T_{2}-\bar{t}_{2}\right)}}{8 c}\right) e^{-r \bar{t}_{2}} \Phi(\sigma)
$$

and thus, we can have Proposition (ii) as

$$
\begin{cases}\frac{\partial E\left[J_{2}^{*}\left(0, \tilde{\mathbf{t}}_{1}, \mathbf{T}_{1}\right)\right]}{\partial \bar{t}_{2}} \geq 0, & \text { if } \quad v \geq 2 e^{r\left(T_{2}-\bar{t}_{2}\right)} \sqrt{2 c f} \\ \frac{\partial E\left[J_{2}^{*}\left(0,,_{1}, \mathbf{T}_{1}\right)\right]}{\partial \bar{t}_{2}}<0, & \text { if } \quad v<2 e^{r\left(T_{2}-\bar{t}_{2}\right)} \sqrt{2 c f}\end{cases}
$$

We also have the response function of the expected profit to the variance $\sigma$ as

$$
\frac{\partial E\left[J_{2}^{*}\left(0, \tilde{\mathbf{t}}_{1}, \mathbf{T}_{1}\right)\right]}{\partial \sigma}=-\frac{e^{-r \bar{t}_{2}}}{r}\left(\frac{v^{2} e^{-2 r\left(T_{2}-\bar{t}_{2}\right)}}{8 c}+f\right) \frac{d \Phi(\sigma)}{d \sigma}<0
$$

We can see that it has a nonpositive value and obtain Proposition 2 (iii).

Proof of Proposition 3. The condition for the owner to choose a two-year project is given by considering the difference of the expected benefits, i.e., $\Delta E\left[V^{*}\right] \geq 0$. Equation (44) yields

$$
\begin{cases}\Delta E\left[V^{*}\right] \geq 0 \quad \text { if } \quad \bar{t}_{2} \leq \frac{1}{r}\left\{\ln \left\{e^{r T_{2}}-\left(e^{2 r\left(T_{2}-T_{1}\right)}-1\right)\left(e^{r T_{1}}-1\right)\right\}-\ln \Phi(\sigma)\right\} \\ \Delta E\left[V^{*}\right]<0 \quad \text { if } \quad \bar{t}_{2}>\frac{1}{r}\left\{\ln \left\{e^{r T_{2}}-\left(e^{2 r\left(T_{2}-T_{1}\right)}-1\right)\left(e^{r T_{1}}-1\right)\right\}-\ln \Phi(\sigma)\right\}\end{cases}
$$

We can have Proposition 3 from Equations (2) and (A10).

Proof of Proposition 4. The threshold value of $\bar{t}_{2}$ that characterize the sign of $\Delta E\left[V^{*}\right] \geq 0$ can be obtained as follows

$$
\begin{cases}\Delta E\left[x^{*}\right] \geq 0 \quad \text { if } \quad \bar{t}_{2} \leq \frac{1}{r}\left\{\ln \left(e^{r\left(T_{2}-T_{1}\right)}+e^{r T_{1}}-1\right)-\ln \Phi(\sigma)\right\} \\ \Delta E\left[x^{*}\right]<0 \quad \text { if } \quad \bar{t}_{2}>\frac{1}{r}\left\{\ln \left(e^{r\left(T_{2}-T_{1}\right)}+e^{r T_{1}}-1\right)-\ln \Phi(\sigma)\right\}\end{cases}
$$

Now, $\zeta_{\left[E\left[x_{2}^{*}\right]=x_{1}^{*}\right]}$ can be obtained by considering Equation (2) and the threshold value of $\bar{t}_{2}$ in Equation (A11). Furthermore, $\zeta_{\left[E\left[V_{2}^{*}\right]=V_{1}^{*}\right]}$ can be rewritten as follows:

$$
\begin{array}{r}
\zeta\left[E\left[V_{2}^{*}\right]=V_{1}^{*}\right]=\frac{1}{r} \ln \left\{e^{r\left(T_{2}-T_{1}\right)}+e^{r T_{1}}-1-\left(e^{r T_{2}}-e^{r\left(T_{2}-T_{1}\right)}\right)\left(e^{r\left(T_{2}-T_{1}\right)}-1\right)\right\} \\
-\frac{1}{r} \ln \Phi(\sigma)-T_{1}
\end{array}
$$


Comparing with Equations (47) and (A12), we can see that $\zeta_{\left[E\left[V_{2}^{*}\right]=V_{1}^{*}\right]}$ is smaller than $\zeta_{\left[E\left[x_{2}^{*}\right]=x_{1}^{*}\right]}$ because the fourth term in the natural logarithm of Equation (A12) is negative under the condition of $T_{2}>T_{1}$.

Proof of Proposition 5. The differentiation of $\zeta_{\left[E\left[V_{2}^{*}\right]=V_{1}^{*}\right]}$ with respect to $\sigma$ yields

$$
\frac{d \zeta_{\left[E\left[V_{2}^{*}\right]=V_{1}^{*}\right]}}{d \sigma}=\frac{d \zeta_{\left[E\left[x_{2}^{*}\right]=x_{1}^{*}\right]}}{d \sigma}=-\frac{1}{r \Phi(\sigma)} \frac{d \Phi(\sigma)}{d \sigma}<0
$$

Proof of Proposition 6. First, we define the following function $\Delta E\left[J^{*}\right]$ to characterize the relative size of the expected profits

$$
\begin{aligned}
& \left.\Delta E\left[J^{*}\right]=E\left[J_{2}^{*}\left(0, \tilde{\mathbf{t}}_{1}, \mathbf{T}_{1}\right)\right]-J_{1}^{*}\left(0, t_{1}, T_{1}\right)\right) \\
= & \frac{v^{2}}{8 c r}\left\{e^{-2 r T_{2}}\left(e^{r T_{1}}-1+e^{r T_{2}}-e^{r \bar{t}_{2}} \Phi(\sigma)\right)-e^{-2 r T_{2}}\left(e^{r T_{1}}-1\right)\right\}-\frac{f}{r}\left(e^{-r \bar{t}_{2}} \Phi(\sigma)-e^{-r T_{2}}\right)
\end{aligned}
$$

Proof of Proposition 6 (i): When the owner orders the one-year project, the condition for the contractor implementing the one-year project is given by

$$
v \geq v_{\left[J_{1}^{*}=0\right]} \equiv 2 \sqrt{2 c f e^{r T_{1}}}
$$

If the project values satisfies this condition, then it is profitable for the contractor to implement this project, i.e., $\left.J_{1}^{*}\left(0, t_{1}, T_{1}\right)\right) \geq 0$. In Equation (A14), the first term becomes negative when $E\left[V_{2}^{*}\left(T_{2}\right)\right] \leq V_{1}^{*}\left(T_{1}\right)$, so $\Delta E\left[J^{*}\right]$ is always negative. It implies that the contractor obtains a larger expected profit by implementing the one-year project. Thus, Equation (A15) holds and the contractor implements the one-year project and then prefers the one-year project to the two-year project.

Proof of Proposition 6 (ii): When the owner orders the two-year project, the condition for the contractor implementing the two-year project is given by $E\left[J_{2}^{*}\left(0, \tilde{\mathbf{t}}_{1}, \mathbf{T}_{1}\right)\right] \geq 0$ and it is written as

$$
\begin{cases}E\left[J_{2}^{*}\left(0, \tilde{\mathbf{t}}_{1}, \mathbf{T}_{1}\right)\right] \geq 0, \quad \text { if } \quad v \geq v_{\left[E\left[J_{2}^{*}\right]=0\right]} \\ E\left[J_{2}^{*}\left(0, \tilde{\mathbf{t}}_{1}, \mathbf{T}_{1}\right)\right]<0, \quad \text { if } \quad v<v_{\left[E\left[J_{2}^{*}\right]=0\right]}\end{cases}
$$

where,

$$
v_{\left[E\left[J_{2}^{*}\right]=0\right]}=2 e^{r T_{2}} \sqrt{2 c f \frac{1-e^{-r T_{1}}+e^{-r \bar{t}_{2}} \Phi(\sigma)-e^{-r T_{2}}}{e^{r T_{1}}-1+e^{r T_{2}}-e^{r \bar{t}_{2}} \Phi(\sigma)}}
$$

And from Equation (A14), the condition for $E\left[J_{2}^{*}\left(0, \tilde{\mathbf{t}}_{1}, \mathbf{T}_{1}\right)\right]$ to be larger than $J_{1}^{*}\left(0, t_{1}, T_{1}\right)$ is given by

$$
\left\{\begin{array}{lll}
E\left[J_{2}^{*}\left(0, \tilde{\mathbf{t}}_{1}, \mathbf{T}_{1}\right)\right] \geq J_{1}^{*}, & \text { if } & v \geq v_{\left[E\left[J_{2}^{*}\right]=J_{1}^{*}\right]} \\
E\left[J_{2}^{*}\left(0, \tilde{\mathbf{t}}_{1}, \mathbf{T}_{1}\right)\right]<J_{1}^{*}, & \text { if } & v<v_{E\left[\left[J_{2}^{*}\right]=J_{1}^{*}\right]}
\end{array}\right.
$$

where,

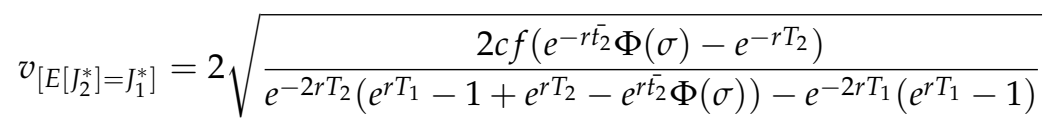

Here, we consider the following lemma to characterize the relative size of $v_{\left[E\left[J_{2}^{*}\right]=J_{1}^{*}\right]}$, $v_{\left[E\left[J_{2}^{*}\right]=0\right]}$, and $v_{\left[J_{1}^{*}=0\right]}$.

Lemma A1. Under the condition of $E\left[V_{2}^{*}\left(T_{2}\right)\right] \geq V_{1}^{*}\left(T_{1}\right)$, it holds that

$$
v_{\left[E\left[J_{2}^{*}\right]=J_{1}^{*}\right]}>v_{\left[E\left[J_{2}^{*}\right]=0\right]}>v_{\left[J_{1}^{*}=0\right]}
$$


Thus, if $v>v_{\left[E\left[J_{2}^{*}\right]=J_{1}^{*}\right]}$ holds, the contractor implements the two-year project and prefers the two-year project to the one-year project. Furthermore, if $v_{\left[E\left[J_{2}^{*}\right]=J_{1}^{*}\right]}>v>$ $v_{\left[E\left[J_{2}^{*}\right]=0\right]}$ holds, although the contractor prefers the one-year project, the owner requests the contractor to implement the two-year project.

\section{Appendix A.2. Numerical Setting for Each Figure}

The following Table A1 shows the numerical setting from Figures 2-7. It shows a situation where a project can proceed for 28 weeks out of 52 weeks in a year, and it must be suspended for 24 weeks as the standard case.

Table A1. Parameter setting for each figure.

\begin{tabular}{|c|c|c|c|c|c|c|}
\hline Parameter & Figure 2 & Figure 3 & Figure 4 & Figure 5 & Figure 6 & Figure 7 \\
\hline$r$ & 0.003 & 0.003 & 0.003 & 0.003 & 0.003 & 0.003 \\
\hline$T_{1}$ & 28 & 28 & 28 & 28 & 28 & 28 \\
\hline $\bar{\zeta}_{1}$ & $\begin{array}{l}\text { Equations (45) } \\
\text { and (47) }\end{array}$ & $\begin{array}{l}\text { Equations (45) } \\
\text { and (47) }\end{array}$ & 24 & 36 & 24 & 24 \\
\hline$T_{2}$ & {$[52,75]$} & {$[52,70]$} & 80 & 70 & 80 & 80 \\
\hline $\bar{\sigma}$ & 0 & 24 & {$[0,24]$} & 2 & 24 & {$[0,24]$} \\
\hline$v$ & - & - & 1 & $\begin{array}{l}\text { Equations (A15), } \\
\text { (A17) and (A19) }\end{array}$ & $\begin{array}{l}\text { Equations (A15), } \\
\text { (A17) and (A19) }\end{array}$ & 1 \\
\hline$c$ & - & - & 1 & 1 & 1 & 1 \\
\hline$f$ & - & - & - & {$[0,1.0]$} & {$[0,1.0]$} & 1 \\
\hline
\end{tabular}

\section{References}

1. Sachs, J.; Kroll, C.; Lafortune, G.; Fuller, G.; Woelm, F. Sustainable Development Report 2021; Cambridge University Press: Cambridge, UK, 2021. [CrossRef]

2. Shane, J.S.; Molenaar, K.R.; Anderson, S.; Schexnayder, C. Construction Project Cost Escalation Factors. J. Manag. Eng. 2009, 25, 221-229. [CrossRef]

3. Wambeke, B.W.; Hsiang, S.M.; Liu, M. Causes of Variation in Construction Project Task Starting Times and Duration. J. Constr. Eng. Manag. 2011, 137, 663-677. [CrossRef]

4. Larsen, J.K.; Shen, G.Q.; Lindhard, S.M.; Brunoe, T.D. Factors Affecting Schedule Delay, Cost Overrun, and Quality Level in Public Construction Projects. J. Manag. Eng. 2016, 32, 04015032. [CrossRef]

5. Long, N.D.; Ogunlana, S.; Quang, T.; Lam, K.C. Large construction projects in developing countries: A case study from Vietnam. Int. J. Proj. Manag. 2004, 22, 553-561. [CrossRef]

6. Doloi, H.; Sawhney, A.; Iyer, K.C.; Rentala, S. Analysing factors affecting delays in Indian construction projects. Int. J. Proj. Manag. 2012, 30, 479-489. [CrossRef]

7. Al-Hazim, N.; Salem, Z.A.; Ahmad, H. Delay and Cost Overrun in Infrastructure Projects in Jordan. Procedia Eng. 2017, 182, 18-24. [CrossRef]

8. Elinwa, U.A.; Joshua, M. Time-Overrun Factors in Nigerian Construction Industry. J. Constr. Eng. Manag. 2001, 127, 419-425. [CrossRef]

9. Flyvbjerg, B.; Holm, M.S.; Buhl, S. Underestimating costs in public works projects: Error or lie? J. Am. Plan. Assoc. 2002, 68, 279-295. [CrossRef]

10. Fukubayashi, Y.; Kimura, M. Spot Improvement of Rural Roads Using a Local Resource-Based Approach: Case Studies from Asia and Africa; In International Development; Appiah-Opoku, S., Ed.; IntechOpen: London, UK, 2017. [CrossRef]

11. Hazır, Ö.; Ulusoy, G. A classification and review of approaches and methods for modeling uncertainty in projects. Int. J. Prod. Econ. 2019, 223, 107522. [CrossRef]

12. Acebes, F.; Pajares, J.; Galán, J.M.; López-Paredes, A. Exploring the Influence of Seasonal Uncertainty in Project Risk Management. Procedia Soc. Behav. Sci. 2014, 119, 329-338. [CrossRef]

13. Icmeli-Tukel, O.; Rom, W.O. Ensuring quality in resource constrained project scheduling. Eur. J. Oper. Res. 1997, 103, 483-496. [CrossRef]

14. Kim, J.Y.; Kang, C.W.; Hwang, I.K. A practical approach to project scheduling: Considering the potential quality loss cost in the time-cost tradeoff problem. Int. J. Proj. Manag. 2012, 30, 264-272. [CrossRef]

15. Bordley, R.F.; Keisler, J.M.; Logan, T.M. Managing projects with uncertain deadlines. Eur. J. Oper. Res. 2019, $274,291-302$. [CrossRef]

16. Gutierrez, G.J.; Kouvelis, P. Parkinson's Law and Its Implications for Project Management. Manag. Sci. 1991, 37, 990-1001. [CrossRef] 
17. Bellman, R.; Kalaba, R. A note on interrupted stochastic control processes. Inf. Control 1961, 4, 346-349. [CrossRef]

18. Schwartz, E.S.; Zozaya-Gorostiza, C. Investment under uncertainty in information technology: Acquisition and development projects. Manag. Sci. 2003, 49, 57-70. [CrossRef]

19. Mok, K.Y.; Shen, G.Q.; Yang, J. Stakeholder management studies in mega construction projects: A review and future directions. Int. J. Proj. Manag. 2015, 33, 446-457. [CrossRef]

20. Ceric, A. Application of the principal-agent theory to construction management: Literature review. In Proceedings of the 29th Annual ARCOM Conference, Reading, UK, 2-4 September 2013; Smith, S.D., Ahiaga-Dagbui, D.D., Eds.; Association of Researchers in Construction Management: Edinburgh, UK, 2013; pp. 1071-1081.

21. Zhu, J.; Hertogh, M.; Zhang, J.; Shi, Q.; Sheng, Z. Incentive Mechanisms in Mega Project-Risk Management Considering Owner and Insurance Company as Principals. J. Constr. Eng. Manag. 2020, 146, 04020120. [CrossRef]

22. Deng, S.; Sheng, C.; Yang, N.; Song, L.; Huang, Q. Anthropogenic forcing enhances rainfall seasonality in global land monsoon regions. Environ. Res. Lett. 2020, 15, 104057. [CrossRef]

23. Maure, G.; Pinto, I.; Ndebele-Murisa, M.; Muthige, M.; Lennard, C.; Nikulin, G.; Dosio, A.; Meque, A. The southern African climate under $1.5^{\circ} \mathrm{C}$ and $2{ }^{\circ} \mathrm{C}$ of global warming as simulated by CORDEX regional climate models. Environ. Res. Lett. 2018, 13, 065002. [CrossRef]

24. Kamien, M.I.; Schwartz, N.L. Dynamic Optimization: The Calculus of Variations and Optimal Control in Economics and Management, 2nd ed.; Elsevier Science: Amsterdam, The Netherlands, 1991.

25. Bertsekas, D.P. Dynamic Programming and Optimal Control, 3rd ed.; Athena Scientific: Belmont, MA, USA, 2005; Volume I.

26. Plaza, Á. Proof Without Words: Exponential Inequalities. Math. Mag. 2008, 81, 374. [CrossRef] 